УДК 94(569.4)

DOI: $10.52575 / 2687-0967-2021-48-1-36-47$

\title{
«День розы» как пример трансформации языческих праздников в ранневизантийской Газе
}

\author{
М.Ю. Лопатина \\ Белгородский государственный национальный исследовательский университет, \\ Россия, 308015, г. Белгород, ул. Победы, 85 \\ E-mail: 820301@bsu.edu.ru
}

\begin{abstract}
Аннотация. В данной статье, на основании диалексисов Прокопия Газского, анализируется праздник день poзbl, который ежегодно проходил в Газе Палестинской. Этот праздник также упоминается в сочинениях Иоанна Газского и Георгия Грамматика. День розы сочетал в себе как языческий фестиваль «маюма», открытый для светской публики, так и празднество в честь христианских мучеников, сопровождавшееся религиозными обрядами. На данном празднике (день poзы) проводились конкурсы ораторского мастерства, а также давались пантомимические представления, которые во многом объясняют цель и стиль изложения Прокопием своих диалексисов. Кроме того, на основе отсылок ритора к Платону, рассматривается предположение исследователей об Эросе как предфигурации христианской агапы.
\end{abstract}

Ключевые слова: Прокопий Газский, день розы, фестиваль, агапа, маюма, розалии.

Для цитирования: Лопатина М.Ю. 2021. День розы» как пример трансформации языческих праздников в ранневизантийской Газе. Via in tempore. История. Политология, 48 (1): 36-47. DOI: $10.52575 / 2687-0967-2021-48-1-36-47$.

\section{«Dies Rosarum» as an example of transformation of pagan festivals in early Byzantine Gaza}

\author{
Marina Yu. Lopatina \\ Belgorod National Research University, \\ 85 Pobeda St., Belgorod, 308015, Russia \\ E-mail: 820301@bsu.edu.ru
}

\begin{abstract}
Annotation. This article analyses the dies rosarum Festival, which took place annually in Gaza of Palestine. The declamations of Procopius of Gaza are chosen as the main historical sources. The holiday is also mentioned in the writings of John of Gaza and George Grammaticus. The dies rosarum combined a pagan festival «maiuma», that was open to the secular public, and a celebration in honor of martyrs, accompanied by the religious rites. During this holiday (dies rosarum) competitions of oratory skills were held, as well as pantomimic performances, which in most explain the purpose and style of Procopius's presentation of his declamations. Moreover, the researchers' assumption of Eros as a pre-configuration of the Christian agape is considered based on the rhetorician's references to Plato. The works of Procopius of Gaza as partly of other representatives of the Gaza school, make it possible to reconstruct the existence of a number of phenomena that can serve as an example of early Byzantine cultural synthesis, which absorbed both ancient and Christian features.
\end{abstract}

Keywords: Procopius of Gaza, dies rosarum, festival, agapa, Maiumas, Rosalia.

For citation: Lopatina M.Yu. «Dies Rosarum» as an example of transformation of pagan festivals in early Byzantine Gaza. Via in tempore. History and political science, 48 (1): 36-47 (in Russian). DOI: $10.52575 / 2687-0967-2021-48-1-36-47$. 


\section{Введение}

Газа Палестинская с древнейших времен славилась своими праздниками. Как и во всех городах средиземноморского побережья, в этом месте царило сезонное торжество весны, олицетворением которого был праздник маюма, часто заканчивавшийся ритуалом зажжения ярких огней и иллюминацией. Постепенно языческий характер этих торжеств был элиминирован, а все, что было совместимо с христианской религией, сохранилось. Например, при Юстиниане целью фестиваля ${ }^{7}$ нередко было открытие церкви или какоголибо общественного памятника. И, так как пантомимы и кровавая травля зверей попадали под запрет, еще большее значение приобретали литературные (риторические) состязания. Если обратиться в данном контексте к творчеству христианского ритора Прокопия Газского (ок. 475 - ок. 528), то можно увидеть, что большинство из его сохранившихся сочинений были связаны с контекстом празднования дня розы [Procopii Gazaei, 1963, p. 52-53]. Сразу стоит заметить, что данный фестиваль вызывает ряд вопросов. Следует ли считать его автономным событием или его необходимо прослеживать в более широком праздничном контексте одного из многочисленных торжеств, которые проходили в городе Газа? И в какое время года он праздновался? К сожалению, Прокопий не дает нам точного ответа на данные вопросы. Но на основании имеющихся источников мы можем сделать попытку решить поставленные проблемы.

\section{Объекты и методы исследования}

Для решения поставленных задач нами был использован историко-системный метод, позволяющий выделить фестиваль «день розы» из всего многообразия праздников Ранней Византии. Удалось установить языческие праздники, на основе которых сформировалось данное торжество, и что определяло его целостность. Контент-анализ сочинений Прокопия даёт возможность проследить, какими мероприятиями сопровождался день розыl. С помощью ретроспективного метода мы показываем, что день чествования христианских мучеников, проходивший в христианизированной Газе, генетически восходил к античному празднику Розалии.

\section{Результаты и их обсуждение}

Отметим, что историография об античных праздниках в целом недостаточно обширна: она носит либо обобщающий характер, либо посвящена конкретным фестивалям [Tomascheck, 1868; Drexles, 1886; Perdrizet, 1900; Saglio, 1904; Hild, 1919; Nilsson, 1920; Preisendanz-Jacoby, 1928; Abel, 1931; Nilsson, 1951; Listas, 1982; Caimi, 1985; Kokkinia, 1999; Belayche, 2004; Chuvin, 2009 и др.]. В творчестве газских риторов доминирующей темой является наступление весны. Например, в некоторых стихах Иоанна Газского, явно составленных по случаю праздника дня poзbl, повторяются некоторые выражения, относящиеся к весне (Jo. Gaz., Anacr. 4, 1-2. 10-11 и 15-16; 5, 1-3. 17-24). В связи с этим В. Томашек выдвинул предположение, что день розы можно отождествить с весенним сезонным праздником чествования памяти умерших Розалии, популярным в греко-римском мире [Tomascheck, 1868, p. 369-371]. С распространением христианства он приобрел ценность для новой религии и все больше и больше связывался с культом мертвых. Действительно, «весенний сезон, в котором цветы выходят из земли, знаменует [...] этап возвращения мертвых» [Chirassi, 1968, p. 117]. Данная точка зрения была поддержана некоторыми другими учеными [Glücker, 1987, р. 54; Garzya, 1998, p. 442; Garzya - Loenertz, 1963, p. XXXV]. Однако Д. Вестберг указал, что присутствие розы само по себе не является до-

7 Термин «фестиваль» распространен в зарубежной научной литературе для обозначения античного празднества, состязания. В отечественной историографии он стал использоваться лишь недавно. Здесь используется нами как синоним праздника. 
статочным аргументом [Westberg, 2010, p. 178]. Также было отмечено, что Розалии в ранневизантийской Газе носили по существу похоронный характер [Ciccolella, 2000, p. 144]. Однако последний аргумент остался единичным, так как в Поздней античности это был преимущественно радостный и яркий сезонный праздник.

Изначально Розалии - праздник профанный, светский, отмечаемый на частных пиршествах. В Риме он попадал в категорию sacra privata (священный частный) без какойлибо связи с культом мертвых [Hild, 1919, col. 1112]. Благодаря характеру светского народного праздника он не только сохранился, причем в одном контексте с погребальным культом [Nilsson, 1951, p. 312-313], но и был защищен как таковой законом - Кодексом Феодосия (Cod. Theod. XVI, 10, 17). Погребальный аспект отсутствует у Прокопия, а также у Иоанна Газского и Георгия Грамматика (в данном контексте они рассматривают лишь смерть Адониса). И это неудивительно, так как риторы традиционно были ориентированы на публичное выступление, предусматривающее «поэтические и литературные состязания, направленные на воспевание весны и розы» [Ciccolella, 2000, p. 144], и мифы, с ними связанные, а отнюдь не на скорбь погребения. Традиция побуждает Прокопия в Dial. 3 молиться о приходе весны, чтобы он снова мог «воспеть розу», вспоминая, как «даже сейчас речи усыпаны розами, с которыми приходит изящество и элегантность» (Ор. III, 67-70). Прокопием также были составлены еще два сочинения на близкую тему, вероятно, прочитанные в рамках одного праздника, в ночное время [Ciccolella, 2000, p. 71].

Существует мнение о том, что день роз - это переосмысление праздника маюма или некая его адаптация применительно к новому времени [Gaggiotti, 1990, p. 238]. Маюма упоминается Иоанном Малалой в Антиохии как драматический ночной праздник, посвященный тайнам Диониса и Афродиты, во время которого даются театральные представления (вероятно, пантомимические) [Belayche, 2004, p. 17] по событиям, связанным с мифом о почитаемых божествах. Праздник был запрещен императорским указом (Cod. Theod. XVI, 6, 1, 2), но все ещё продолжал отмечаться даже в VIII веке [Theophanes, 1841, p. 451, 24-26].

Однако празднование маюмы в Антиохии и Газе достаточно ощутимо разнилось. В Антиохии фестиваль проходил один раз в три года; важное место на нем отводилось как Афродите, так и Дионису. В Газе же маюма праздновалась ежегодно (Georg. Gramm., Anacr. 1, 53-54); роль Диониса по сравнению с ролью Афродиты резко снижается. Бог виноделия упоминается Прокопием только в Ор. III, 66. Кроме того, лишь название утраченной этопеи Иоанна Газского «Какие слова сказал бы Дионис, когда придет весна», указывает на роль бога виноделия в контексте газских маюм [Ciccolella, 2000, p. 173].

Н. Белейш была выдвинута гипотеза, согласно которой маюма представляет собой общее название типа фестиваля, характерного для сирийско-палестинской области с учетом незначительных локальных компонентов, ориентированного на смену сезонов, присутствие водной стихии и широко распространенную публичную радость. Дата празднования варьировалась в каждом отдельном городе, где благодаря эллинизированным формам восточных ритуалов и в связи с театральными играми почитались различные божества, характеризующиеся культом и/или мифологическим рассказом, сосредоточенным вокруг водной стихии [Belayche, 2004, p. 19]. Это относится в первую очередь к Афродите, рожденной из пены морской. Сам Прокопий в своих диалексисах несколько раз упоминает этот аспект мифологии, представляя богиню в окружении нереид и дельфинов, а также в колеснице, запряженной тритонами (Procop. Gaz., Op. I, 2-4; III, 5-15).

Доминирование любовной истории между Адонисом и Афродитой в творчестве риторов в контексте данного праздника заставляет задуматься о дате его проведения. Из сочинений Прокопия, Иоанна и Георгия Грамматика мы можем извлечь, помимо самого элемента истории Адониса и Афродиты, некоторые хронологические указания. В частности, Георгий Грамматик ссылается на летнее время, в момент, когда «земля увенчана колосьями» (Georg. Gramm., Anacr. 1, 57). Он также ясно указывает на культ Адониса и Аф- 
родиты, который когда-то имел место в святилище Афаки в Финикии Ливанской [Сісcolella, 2000, p. 186-187]. Иоанн Газский в своих стихах ссылается на весенний сезон в контексте праздника [Ciccolella, 2000, p. 3]. Прокопий же указывает как на весну в качестве фона для своих сочинений, так и на лето (Рrocop. Gaz., Op. IV), так как созерцать на вечернем небе созвездия Ориона, Андромеды и Персея, как правило, можно в летнее время [Ciccolella, 2000, p. 273]. Данное противоречие, по всей видимости, может быть разрешено предположением, что день роз в честь Адониса и Афродиты мог проходить два раза в год, весной и летом [Lambrechts, 1953, p. 220].

Прежде всего следует подчеркнуть, что даже при отсутствии непосредственных свидетельств [Belayche, 2004, p. 15], которые позволили бы проследить, как считалось в прошлом, происхождение маюмы именно в Газе [Belayche, 2004, p. 19], генезис такого праздника в палестинском городе представляется весьма вероятным. Сам Прокопий прямо ссылается на это в письме Диодору, где подчеркивает, что его собеседник не вернулся в Газу в праздничный день чествования мучеников, но мечтая о маюме, фестивале светского характера, сопровождающего религиозный праздник, который представлял все же заманчивый предлог для его возвращения в город: «Я думал, что ты отпразднуешь здесь у нас праздник мучеников и позволишь нам, наконец, увидеть тебя; а ты, хотя и видишь во сне маюмы, по-видимому, испытываешь к нему досаду и, боясь предзнаменования, называешь этот день гнусным» (Procop. Gaz., Ep. 77, 1-3).

Присутствие в христианском масштабном празднике профанного элемента, более радостного и веселящего, чем это следовало бы на таком празднике, подробно засвидетельствовано в источниках. Св. Августин, например, вспоминая Розалии в Карфагене, явно намекает, без всякого презрения, на веселье, которое это празднование вызывало в христианской аудитории [Роque, 1971, p. 158]. Иоанн Лид (VI в.) свидетельствует, что в Остии Розалии также имели характер местной маюмы, связанный с более светскими практиками и церемониями [Belayche, 2004, p. 17-18]. Останавливаясь на празднике в честь мучеников, Августин свидетельствует нам, что они часто сопровождались одновременной организацией и представлением пантомим, песен и развлечений всех видов [Saxer, 1980, p. 134-140]. В научной литературе ранее не придавалось реального значения свидетельству Прокопия, которое больше других может помочь нам уточнить характер связи дня роз с праздником святых мучеников в Газе. Другими словами, в позднеантичный период происходила адаптация средиземноморского дня розы к празднику умерших, который отмечался римскими погребальными коллегиями [Waltzing, 1895, p. 143] на общинном пире «с хлебом и вином» еще с I века. Коллегия Эскулапа и Гигиеи, которая проводила семь ежегодных похоронных пиров, праздновала один из них 11 мая, в день розы.

Если допустить, что розы с их шипами и кровь, вытекающая от укола ими (т. е., мифическая история смерти Адониса и последующего отчаяния Афродиты) [Waltzing, 1895, p. 53-54], символизируют для верующих мученичество Иисуса Христа, то уже давно было высказано мнение о том, что день роз в честь умерших со временем у ранних христиан был замещен так называемой агапой в память мучеников [Poque, 1971, p. 159]. Известно, что древние христиане праздновали два вида агапы [Allo, 1934, p. 292]: таинственный, который ознаменовывал Тайную вечерю с Евхаристией, и несакраментальный, собиравший за столом братьев на вечерний ужин («вечеря Господня»). В последнем случае «вино и хлеб, которые были съедены, зажженные свечи и дары, которые были распределены среди участников, скорее приносили облегчение живым, чем мертвым» [Testa, 1976, p. 202].

Быть может, в таком случае Прокопий намекает в Dial. 3 на тайну освящения евхаристического вина? Если это так, то это приводит нас к заключению о том, что день розы, для которого он, как и другие представители Газской школы, сочинил специальные произведения, прямо связан с празднованием дня мучеников, во время которого важным моментом поклонения была Тайная вечеря среди верующих и евхаристическое богослуже- 
ние [Saxer, 1969, p. 194-201]. На такую идентификацию указывают четыре важные особенности:

1. B Dial. 2 (Procop. Gaz., Op. 11) Прокопий описывает, основываясь на платоновском образце «Федра», символический сад, который напоминает Небесный сад, обещанный мученикам. Об этом саде верующие Карфагена каждый год привыкли слушать во время праздника мученику Иакову: «Путь наш проходил по прекрасному месту с лугами, одетому пышной листвой зелёных рощ и покрытому тенью вздымающихся ввысь кипарисов и сосен, касающихся небес» (Passio SS. Marian. et Jacob. 11).

2. Газский софист дает явные коннотации на «Пир» Платона, где показана разница между Афродитой Уранией и Афродитой «обыкновенной» (Procop. Gaz., Op. III). Не случайно, что оба отрывка касаются платонической концепции любви. Бытует мнение, что идея христианской агапы находится под сильным влиянием и интерпретацией идеи эроса у Платона [Nygren, 2011]. Свидетельство Прокопия, до сих пор игнорируемое христианскими учеными, косвенно указывает на связь между Платоном и христианским учением о любви к Богу, представляя в то же время философско-религиозный ключ к интерпретации самих трудов Прокопия.

3. В заключении Dial. 1 (Procop. Gaz., Op. I, 72), а также во 2-й и 3-й этопее (Procop. Gaz., op. V, 59; Op. VI, 62) указывается повод к празднику, где идет отсылка к жертве Иисуса Христа и мучеников [Nygren, 2011, p. 55], а также на «поминальные» обряды, а именно погребальные пиры в честь усопших [Weiss, 1917, p. 506; Lietzmann, 1926, p. 223; Lietzmann, 1969, p. 131-132].

4. В Экфрасисе (Procop. Gaz., Op. IX, 250, 305-320), который, вероятно, также был прочитан в день poзы, Прокопий свидетельствует об объекте иконографии, не засвидетельствованном в других местах, а именно о Дафне как спутнике Ипполита на охоте. Эта неожиданная версия мифа с середины XIX в. пользуется вниманием специалистов. По одному из толкований, в данном случае Дафна представляет собой олицетворение лаврового венка, награду за подвиги и мужественные поступки (охота) [Brunn, 1849, p. 62], а идеалом целомудрия выступает Артемида, заключенная в объятия Ипполита. Возможно, что в свете христианской интерпретации Дафна в Экфрасисе Прокопия является воплощением символа лаврового венка, награды мученичество верующих христиан [Talgam, 2004, p. 34, p. 212].

Трудно представить, что в христианской Газе рубежа V-VI вв. контекст фестиваля дня розы отличался бы от праздника в честь мучеников. Вероятно, праздник имел две отличительные особенности. Первая - частный и строго религиозный характер, где сообщество верующих собиралось по случаю «братского» вечернего ужина и связанных с ним обрядов; вторая - публичный, в форме маюмы, где принимало участие все население города и в котором не исключены были литературные состязания риторико-софистического типа.

Праздник маюмы в Газе, который проходил также, как нам известно из источников, в Антиохии и Остии, должен был включать водные игры, сценические представления и пантомимы. Среди сохранившихся сочинений Прокопия есть упоминания пантомимических репрезентаций [Gianotti, 1991, p. 312-329; Tedeschi, 2002, p. 115-129; Garelli, 2007]. Прокопий как христианин, видимо, стремился расшифровать мифологическое содержание, представленное в танце, которое со временем становилось все меньше и меньше известно христианской публике. Эта практика также засвидетельствована Августином (354-430 гг.), который говорит о том, как в Карфагене глашатай перед спектаклем объявлял зрителям тему самой пантомимы: «Ибо, если бы различные знаки, представляемые, например, танцующими комедиантами, были понятны сами по себе [...] то не было бы, например, нужды, чтобы глашатай народный изъяснял карфагенянам, что хотел подобными знаками выразить один их пантомим, танцевавший пред ними, как об этом доселе рассказывают многие старые люди, от коих и мы это слышали. Да и нечего дивиться в этом 
отношении карфагенянам, когда и теперь еще у нас самих человек неопытный в рассуждении подобных мелочей, войдя в театр, при всем своем внимании не понимает значения действий, представляемых там пантомимами, если кто-либо другой не изъяснит ему оных» [Бл. Аврелий Августин, 1935, II, 38].

Наблюдение Августина, как считал А. Мюллер [Müller, 1909, p. 45], было направлено не только на жестовые излишества пантомимы, но косвенно также на ее отдаленность от массовой культуры населения, которое все меньше и меньше понимало отсылки к языческому мифологическому наследию. М. Гарелли считает, что Августин предпринимает попытку атаковать культурный фон, ставший чуждым массе публики, путем навязывания экзегезы. Он также принимает участие в спорах по важному вопросу - о драматическом танце на основе мифов - популярной основе языческой культуры - и настаивает на отстраненности, дистанции по отношению к этой части культуры его эпохи. По Августину, репрезентация мифа в театре, где проявляется языческая культура, уже не имела смысла для человека V в. [Garelli, 2007, p. 323].

Следовательно, если рассматривать цель и функции трех диалексисов Прокопия (Procop. Gaz., Opp. I-III) с такой точки зрения, то становится понятно, почему не сохранились собственно речи, введением к которым служили диалексисы. Например, у Хорикия все декламации сопровождаются диалексисами. Следует отметить, что в конце некоторых из диалексисов Прокопий предвосхищает ритуальные церемонии, связанные с праздником, или те же пантомимические представления (Procop. Gaz., Opp. II, 102-103 и III, 69-70). Прокопий использует термин, указывающий на песню, сопровождающую пантомиму, его употребляют также Лукиан и Либаний [Garelli, 2007, p. 61].

В диалексисах Прокопия присутствует переизбыток ссылок на мифы, которые являются зачастую предметом мимических танцев [Garelli, 2007, p. 271-280]. Среди них важны описание тела тритонов (Procop. Gaz., Op. III, 13-15), а также «танец» нереид (Procop. Gaz., Opp. I, 3 и III, 13) и трюков в воде дельфинов (Procop. Gaz., Opp. III, 13-15). Учитывая относительно небольшие размеры резервуара с водой, который мог бы находиться внутри орхестры театра, невозможно представить фактическое присутствие дельфинов рядом с танцорами. Более вероятно, что сам пантомимический актер как-то создавал фигуры, показывая плавание дельфинов [Rotolo, 1957, p. 35]. Также упоминаются инструменты - сиринкс (Procop. Gaz., Op. I, 22) и авлос (Procop. Gaz., Op. I, 29), сопровождающие пантомиму [Garelli, 2007, p. 7]. Отсылка на стук ног артистов (Procop. Gaz., Op. I, 47) подразумевает типичный ударный инструмент мимических танцев в виде сандалий с маленькими тарелками, которые издают звук при биении ногами друг о друга [Belis, 1988]. Представление о тех же артистах, обнаженных в пределах приличия (Procop. Gaz., Op. I, 48), говорит о скудной одежде танцоров пантомимы, что яростно критиковалось в христианских кругах.

Миф о Терее, Прокне и Филомеле хорошо подходил для такого рода представлений: актеры не использовали голос, показ перенесенных страданий осуществлялся только с помощью рук, давая возможность показать, что произошло, без слов [Garelli, 2007, p. 329-341]. Поразителен лексикон, используемый Прокопием для описания сцены, где Филомеле удается сообщить сестре Прокне о насилии, совершенном Тереем, который в значительной степени включает в себя все основные компоненты пантомимы (Procop. Gaz., Op. I, 13-15). Даже последующее молчание Прокопия об убийстве Итиса, сына Прокны и Терея (Procop. Gaz., Op. I), делегирующее задачу его воспевания птицам, ставшим свидетелями трагедии, может ссылаться на пение, сопровождающее пантомиму. Все это было типично для данного рода представлений.

У Прокопия отсутствует еще один фундаментальный момент, касающийся пантомимы в соответствии с театральной теорией Аристотеля [Garelli, 2007, p. 343-349]. Он воспроизводит образ танца посредством зрения (Procop. Gaz., Op. I, 26 и 46), а Либаний, например, в своей защите пантомим почти полностью строит свое описание вокруг пуб- 
личного выступления (видел, увидел, показал) (Lib., Or. 64, 67-68). Но даже если мы остановимся на содержании трех прокопиевых диалексисов, которые предстают как яркая пасторальная картина, то придется задуматься о типичном предмете пантомимы. Защищая жанр, Либаний (Lib., Or. 64, 116, 6-12) напоминает о возможности с помощью пантомимического танца посредством движений актеров проиллюстрировать даже статичную пейзажную картину весны: «Какая картина, какая лужайка и зрелище слаще танца и танцора, что приводит зрителя к лесу, заставляет его спать под деревьями, вызывать стада коз и овец, и пастухов, охраняющих собак, звенящую свирель и авлос, в то время как они делают свои дела» [Tedeschi, 2002, p. 119]? За упоминаемым выше предметом пантомимы, безусловно, стоит цветок, который описал древнегреческий грамматик и софист Афиней в произведении «Пир мудрецов»:

Где мои розы? Где мои фиалки?

Где мой сочный сельдерей?

Вот они, розы! Вот мои фиалки!

Вот он, сочный сельдерей! [Афиней, 289]

Среди простых людей ранневизантийского Восточного Средиземноморья также практиковался так называемый танец цветов; они исполняли мимический танец, одновременно напевая такие стихи. По верному замечанию В. Ротоло, существовал некоторый набор цветов, относительно которых песня иллюстрируется танцем [Rotolo, 1957, p. 35].

Исходя из этого, возникает стремление рассмотреть три диалексиса Прокопия, если не совсем как «либретто» для пантомим, то, по крайней мере, как преамбулы вводных руководств к представлению пантомим, которые могли состояться в Газе на фестивале маюмы, в рамках более широкого празднества в честь мучеников [Miles, 1999, p. 276]. На сегодняшний день существуют данные, подтверждающие, что некоторые авторы (Лукиан, Стаций и, вероятно, Августин в юности [Gianotti, Letteratura, 1991, p. 327; Gianotti, Sulle tracce, 1991, p. 147; Garelli, 2007, p. 311-315]) составляли стихи для пантомимических представлений, так называемые fabulae salticae (пьеса с танцами) лирического типа [Jory, 2009].

Произведения подобного жанра, получавшие осуждение со стороны христианских авторов, неудивительны для такого писателя, как Прокопий. Фактически последняя защита мимических представлений и художественного мимесиса, включая пантомиму, возникнет именно в Газской школе в VI в. (уже после смерти Прокопия) через авторитетный голос Хорикия «Речь в защиту тех, кто воспроизводит жизнь в театре Диониса» (Chor., Op. XXXII). Это чрезвычайно важный текст, который доказывает не только то, что подобные выступления были широко распространены в Газе, но и то, что они были любимы преподавателями высшей Школы риторики.

С другой стороны, можно вспомнить, например, случай с Сидонием Аполлинарием, который дал положительную оценку пантомимическому мастерству, а также давнее сочинение Лукиана «О пляске», для которого пантомима представляла собой «сундук с сокровищами» древних и ценных знаний [Santelia, 2008]. Поэтому классически образованные интеллектуалы, которые, как Сидоний, Прокопий и Хорикий, считали классическую традицию непревзойденной моделью обучения и культуры, не могли не сформулировать положительного отзыва о мимическом искусстве в целом, выдвигая в его защиту даже идеи педагогического типа.

Можно также утверждать, что эти настроения шли вразрез с политикой императоров. Так, Анастасий I в 502 г. устроил разбирательство против пантомимических представлений. Данный факт был публично озвучен Прокопием в Панегирике в честь открытия памятника этому императору в Газе (Procop. Gaz., Op. XI, § 16, 351-357). Но мнение Анастасия, разделяемое Прокопием, не затронувшее пантомимические представления 
официально, все же нанесло им удар после народных восстаний, вспыхнувших по случаю гонок на колесницах в 501/502 гг., которые привели, в частности, к смерти его внебрачного сына. Бесчинства этих зрелищ и их участников, которые стали даже лидерами реальных политических фракций - «партий цирка» («зеленые» и «синие») [Croke, 2001, p. 127], не мешают интерпретировать сохранившиеся диалексисы Прокопия как юношеские работы (или предшествующие Панегирику), в которых Прокопий, как и молодой Августин, еще не сформировал зрелого этического взгляда на христианское вероучение.

\section{Заключение}

Критика Прокопия в отношении пантомим была направлена исключительно на представления, актеры которых стремились изображать из себя женщин. Ритор представляет в своих диалексисах более «умеренную» пантомиму, в которой танцоры (а, следовательно, не женоподобные танцоры) выходили на сцену без грима. Имеющиеся у нас тексты приоткрывают именно газскую действительность, а не те зрелища, чьи излишества вызывали недовольство императора Анастасия. Данные, рассмотренные выше в письме Диодору (Procop. Gaz., Ep. 77, 1-3), свидетельствуют о существовании в Газе празднества в честь мучеников, который отмечался вместе с фестивалем маюма. Следовательно, день poзы, на который ссылается Прокопий в своих сочинениях и который упоминается в поэтических стихах Иоанна Газского, нужно рассматривать как адаптацию Розалий, то есть как празднично-священный повод для прославления христианских мучеников через агапе и литературные состязания эпидейктического типа.

\section{Благодарности}

Автор выражает глубокую благодарность научному руководителю, доктору исторических наук, профессору, заведующему кафедрой всеобщей истории Н.Н. Болгову.

\section{Список литературы}

1. Афиней. Пир мудрецов. 2003. Книги I-VIII. Пер. Н.Т. Голинкевича. Комм. М.Г. Витковской, А.А. Григорьевой, Е.С. Иванюк, О.Л. Левинской, Б.М. Никольского, И.В. Рыбаковой. Отв. ред. М.Л. Гаспаров. М., Наука, 656.

2. Афиней. Пир мудрецов. 2010. Книги IX-XV. Пер. и примеч. Н.Т. Голинкевича. М., Наука, 597.

3. Блаженный Аврелий Августин. 1835. Христианская наука или Основания Священной Герменевтики и Церковного красноречия. Киев, Киево-Печерская лавра, 355.

4. Abel F.-M. 1931. Gaza au VIe siècle d'après le rheteur Chorikios. Revue Biblique, 40: 5-31.

5. Allo E.B. 1934. Saint Paul. Premiere epitre aux Corinthiens. Paris, Gabalda, 515.

6. Belayche N. 2007. Des lieux pour le «profane» dans l'Empire tardoantique? Les fêtes entre koinônia sociale et espaces de rivalités religieuses. Antiquité Tardive, 15: 35-46.

7. Belayche N. 2004. Pagan Festivals in the Fourth-Century Gaza. In: Christian Gaza In Late Antiquity. Leiden-Boston, Brill: 5-22. $323-339$.

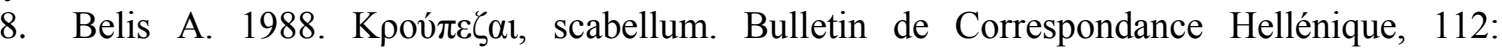

9. Brunn H. 1849. Ippolito. In: Bullettino dell'Instituto di corrispondenza archeologica. Roma, Istituto di Corrispondenza Archeologica: 60-62.

10. Caimi J. 1985. Arcadio Giovanni Crisostomo e la festa de la Maiuma. Annali Della Facolta Di Giurisprudenza, 20: 49-85.

11. Chirassi I. 1968. Elementi di culture precereali nei miti e riti greci. Roma, Edizioni dell'Ateneo, 211.

12. Chuvin P. 2009. Chronique des derniers paiens. La disparition du paganism dans l'Empire romain, du regne de Constantin a celui de Justinien. Paris, Les Belles Lettres, 378. dria, 2000.

13. Cinque poeti bizantini. Anacreontee dal Barberiniano greco 310 / ed. F. Ciccolella. Alessan- 
14. Croke B. 2001. Count Marcellinus and his Chronicle. Oxford: Oxford University Press, 300.

15. Drexles W. 1886. Maiumas. In: Ausführliches Lexikon der griechischen und rümischen Mythologie. B. II. Leipzig, B. G. Teubner Verlag: 2286-2288.

16. Gaggiotti M. 1990. Il Maïuma: una festa dimenticata. Annali della Facoltà di Lettere e Filosofia, 13: 229-242.

17. Garelli M.-H. 2007. Danser le mythe: la pantomime et sa reception dans la culture antique. Louvain, Peeters, 511.

18. Garzya A. 1998. La prosa retorica greca. In: Storia della civiltà letteraria greca e latina. Torino, UTET: 426-445.

19. Gianotti G.F. 1991. Letteratura e spettacoli teatrali in eta imperial. In: Il teatro romano di Trieste. Monumento, storia, funzione. Roma, Istituto svizzero di Roma: 284-329.

20. Gianotti G.F. 1991. Sulle tracce della pantomima greca: Alcesti tra i danzatori? Dioniso, 61: $121-149$.

21. Glucker C.A.M. 1987. The city if Gaza in the Roman and Byzantine periods. Oxford, BAR International Series, 172.

22. Hild J.-A. 1919. Rosaria ou Rosalia. Daremberg-Saglio, IV (2): 895.

23. Jory E.J. 2009. The Pantomime Dancer and his Libretto. In: New Directions in Ancient Pantomime. Oxford, Oxford University Press: 157-168.

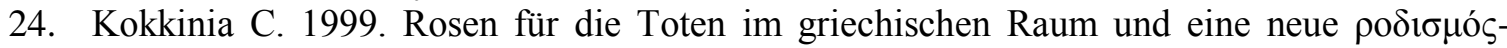
Inschrift aus Bithynien. Museum Helveticum, 56: 204-221.

25. Lambrechts P. 1953. La «resurrection» d'Adonis. AIPhO, 13: 207-240.

26. Lietzmann H. 1969. An die Korinther. Tübingen, Mohr, 224.

27. Lietzmann H. 1926. Messe und Herrenmahl. Eine Studie zur Geschichte der Liturgie. Bonn, Marcus und Weber, 600.

28. Listas F.K. 1982. Festival Choricius of Gaza and his Descriptions of Festivals at Gaza. JÖByz, 32: 427-436.

29. Miles R. 1999. Actors and Acting. In: Late Antiquity. A Guide to the Postclassical World. Cambridge, Mass.-London, Harvard University Press: 276-277.

30. Müller A. 1909. Das Bühnenwesen in der Zeit von Constantin dem Großen bis Justinian. Neue Jahrbücher für das klassische Altertum, 23: 36-55.

31. Nilsson M.P. 1951. Das Rosenfest. Opuscula selecta, 1: 311-329.

32. Nilsson M.P. 1920. Rosalien. RE, I (A): 1111-1115.

33. Nygren A. 2011. Eros e Agape. La nozione cristiana dell'amore e le sue trasformazioni. Bologna, EDB, 848.

34. Perdrizet P. 1900. Les Rosalies. Bulletin de Correspondance Hellénique, 24: 299-323.

35. Poque S. 1971. Des roses du printemps a la rose d'automne. La culture patristique d'Agrippa d'Aubigne. Revue des études augustiniennes, 17: 155-169.

36. Preisendanz K., Jacoby F. 1928. Maïumas. Paulys Realencyclopädie des Klassischen Alterumswissenschaft, XIV: 610-612.

37. Procopii Gazaei Epistolae et Declamationes. Ed. A. Garzya. Ettal, Buch-Kunstverlag, 1963, 111.

38. Rotolo V. 1957. Il pantomimo. Studi e testi. Palermo, Presso l'Accademia, 123.

39. Saglio E. 1904. Maiumas. Dictionnaire des antiquités grecques et romaines, 3 (2): 1555.

40. Santelia S. 2008. Una voce fuori dal "coro": Sidonio Apollinare e gli spectacula theatri (carm. 23, 263-303). Bollettino di studi Latini, 38: 43-56.

41. Saxer V. 1980. Morts Martyrs Reliques en Afrique chrétienne aux premiers siècles: les témoignages de Tertullien, Cyprien et Augustin à la lumière de l'archéologie africaine. Paris, Éd. Beauchesne, 340 .

42. Saxer V. 1969. Vie liturgique et quotidienne à Carthage vers le milieu du IIIe siècle: Le témoignage de saint Cyprien et de ses contemporains d'Afrique. Vaticano, Pontificio Istituto di archeologia cristiana, 450 .

43. Talgam R. 2004. The Ekphrasis Eikonos of Procopius of Gaza: The Depiction of Mythological Themes in Palestine and Arabia during the Fifth and Sixth Centuries. In: Christian Gaza in late antiquity. Leiden-Boston, Brill: 209-234.

44. Tedeschi G. 2002. Lo spettacolo in età ellenistica e tardo antica nella documentazione epigrafica e papiracea. Papirologica Lupiensia, 11: 87-187. 
45. Testa E. 1976. Il Golgota, porto della quiete. In: Studia Hierosolymitana in onore del P. Bellarmino Bagatti: Studi archeologici. Jerusalem, Franciscan Print. Press: 197-244.

46. Theophanes. Chronographia. 1841. Bonnae, Impensis E. Weberi, 592.

47. Tomascheck W. 1868. Über Brumalia und Rosalia nebst Bemerkungen über den bessischen Volksstamm. Sitzungsberichte der Philosophisch-Historischen Klasse der Kaiserlichen Akademie der Wissenschaften, 60: 351-404.

48. Waltzing J.-P. 1895. Etude historique sur les corporations professionnelles chez les romains depuis les origines jusqu'd la chute de l'empire d'occident. Louvain, C. Peeters, 741.

49. Weiss J. 1917. Das Urchristentum. Gottingen, Vandenhoeck \& Ruprecht, 681.

50. Westberg D. 2010. Celebrating with Words: Studies in the Rhetorical Works of the Gaza School. Diss. Uppsala Universiteit, 225.

\section{References}

1. Afinej. Pir mudrecov [Feast of the wise]. 2003. Knigi I-VIII. Per. N.T. Golinkevicha. Komm. M.G. Vitkovskoj, A.A. Grigor'evoj, E.S. Ivanyuk, O.L. Levinskoj, B.M. Nikol'skogo, I.V. Rybakovoj. Otv. red. M.L. Gasparov. M., Nauka, 656.

2. Afinej. Pir mudrecov [Feast of the wise]. 2010. Knigi IX-XV. Per. i primech. N.T. Golinkevicha. M., Nauka, 597.

3. Blazhennyj Avrelij Avgustin. 1835. Hristianskaya nauka ili Osnovaniya Svyashchennoj Germenevtiki i Cerkovnogo krasnorechiya [Christian Science or Foundations of Sacred Hermeneutics and Ecclesiastical Eloquence]. Kiev, Kievo-Pecherskaya lavra, 355.

4. Abel F.-M. 1931. Gaza au VIe siècle d'après le rheteur Chorikios. Revue Biblique, 40: 5-31.

5. Allo E.B. 1934. Saint Paul. Premiere epitre aux Corinthiens. Paris, Gabalda, 515.

6. Belayche N. 2007. Des lieux pour le «profane» dans l'Empire tardoantique? Les fêtes entre koinônia sociale et espaces de rivalités religieuses. Antiquité Tardive, 15: 35-46.

7. Belayche N. 2004. Pagan Festivals in the Fourth-Century Gaza. In: Christian Gaza In Late Antiquity. Leiden-Boston, Brill: 5-22.

8. Belis A. 1988. Kрov́ $\pi \varepsilon \zeta \alpha 1$, scabellum. Bulletin de Correspondance Hellénique, 112: $323-339$.

9. Brunn H. 1849. Ippolito. In: Bullettino dell'Instituto di corrispondenza archeologica. Roma, Istituto di Corrispondenza Archeologica: 60-62.

10. Caimi J. 1985. Arcadio Giovanni Crisostomo e la festa de la Maiuma. Annali Della Facolta Di Giurisprudenza, 20: 49-85. neo, 211.

11. Chirassi I. 1968. Elementi di culture precereali nei miti e riti greci. Roma, Edizioni dell'Ate-

12. Chuvin P. 2009. Chronique des derniers paiens. La disparition du paganism dans l'Empire romain, du regne de Constantin a celui de Justinien. Paris, Les Belles Lettres, 378. dria, 2000.

13. Cinque poeti bizantini. Anacreontee dal Barberiniano greco 310 / ed. F. Ciccolella. Alessan-

14. Croke B. 2001. Count Marcellinus and his Chronicle. Oxford: Oxford University Press, 300.

15. Drexles W. 1886. Maiumas. In: Ausführliches Lexikon der griechischen und rümischen Mythologie. B. II. Leipzig, B. G. Teubner Verlag: 2286-2288.

16. Gaggiotti M. 1990. Il Maïuma: una festa dimenticata. Annali della Facoltà di Lettere e Filosofia, 13: 229-242.

17. Garelli M.-H. 2007. Danser le mythe: la pantomime et sa reception dans la culture antique. Louvain, Peeters, 511.

18. Garzya A. 1998. La prosa retorica greca. In: Storia della civiltà letteraria greca e latina. Torino, UTET: 426-445.

19. Gianotti G.F. 1991. Letteratura e spettacoli teatrali in eta imperial. In: Il teatro romano di Trieste. Monumento, storia, funzione. Roma, Istituto svizzero di Roma: 284-329.

20. Gianotti G.F. 1991. Sulle tracce della pantomima greca: Alcesti tra i danzatori? Dioniso, 61: $121-149$.

21. Glucker C.A.M. 1987. The city if Gaza in the Roman and Byzantine periods. Oxford, BAR International Series, 172.

22. Hild J.-A. 1919. Rosaria ou Rosalia. Daremberg-Saglio, IV (2): 895. 
23. Jory E.J. 2009. The Pantomime Dancer and his Libretto. In: New Directions in Ancient Pantomime. Oxford, Oxford University Press: 157-168.

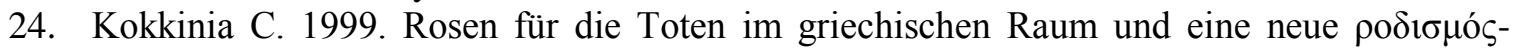
Inschrift aus Bithynien. Museum Helveticum, 56: 204-221.

25. Lambrechts P. 1953. La «resurrection» d'Adonis. AIPhO, 13: 207-240.

26. Lietzmann H. 1969. An die Korinther. Tübingen, Mohr, 224.

27. Lietzmann H. 1926. Messe und Herrenmahl. Eine Studie zur Geschichte der Liturgie. Bonn, Marcus und Weber, 600.

28. Listas F.K. 1982. Festival Choricius of Gaza and his Descriptions of Festivals at Gaza. JÖByz, 32: 427-436.

29. Miles R. 1999. Actors and Acting. In: Late Antiquity. A Guide to the Postclassical World. Cambridge, Mass.-London, Harvard University Press: 276-277.

30. Müller A. 1909. Das Bühnenwesen in der Zeit von Constantin dem Großen bis Justinian. Neue Jahrbücher für das klassische Altertum, 23: 36-55.

31. Nilsson M.P. 1951. Das Rosenfest. Opuscula selecta, 1: 311-329.

32. Nilsson M.P. 1920. Rosalien. RE, I (A): 1111-1115.

33. Nygren A. 2011. Eros e Agape. La nozione cristiana dell'amore e le sue trasformazioni. Bologna, EDB, 848.

34. Perdrizet P. 1900. Les Rosalies. Bulletin de Correspondance Hellénique, 24: 299-323.

35. Poque S. 1971. Des roses du printemps a la rose d'automne. La culture patristique d'Agrippa d'Aubigne. Revue des études augustiniennes, 17: 155-169.

36. Preisendanz K., Jacoby F. 1928. Maïumas. Paulys Realencyclopädie des Klassischen Alterumswissenschaft, XIV: 610-612.

37. Procopii Gazaei Epistolae et Declamationes. Ed. A. Garzya. Ettal, Buch-Kunstverlag, 1963, 111.

38. Rotolo V. 1957. Il pantomimo. Studi e testi. Palermo, Presso l'Accademia, 123.

39. Saglio E. 1904. Maiumas. Dictionnaire des antiquités grecques et romaines, 3 (2): 1555.

40. Santelia S. 2008. Una voce fuori dal "coro": Sidonio Apollinare e gli spectacula theatri (carm. 23, 263-303). Bollettino di studi Latini, 38: 43-56.

41. Saxer V. 1980. Morts Martyrs Reliques en Afrique chrétienne aux premiers siècles: les témoignages de Tertullien, Cyprien et Augustin à la lumière de l'archéologie africaine. Paris, Éd. Beauchesne, 340 .

42. Saxer V. 1969. Vie liturgique et quotidienne à Carthage vers le milieu du IIIe siècle: Le témoignage de saint Cyprien et de ses contemporains d'Afrique. Vaticano, Pontificio Istituto di archeologia cristiana, 450 .

43. Talgam R. 2004. The Ekphrasis Eikonos of Procopius of Gaza: The Depiction of Mythological Themes in Palestine and Arabia during the Fifth and Sixth Centuries. In: Christian Gaza in late antiquity. Leiden-Boston, Brill: 209-234.

44. Tedeschi G. 2002. Lo spettacolo in età ellenistica e tardo antica nella documentazione epigrafica e papiracea. Papirologica Lupiensia, 11: 87-187.

45. Testa E. 1976. Il Golgota, porto della quiete. In: Studia Hierosolymitana in onore del P. Bellarmino Bagatti: Studi archeologici. Jerusalem, Franciscan Print. Press: 197-244.

46. Theophanes. Chronographia. 1841. Bonnae, Impensis E. Weberi, 592.

47. Tomascheck W. 1868. Über Brumalia und Rosalia nebst Bemerkungen über den bessischen Volksstamm. Sitzungsberichte der Philosophisch-Historischen Klasse der Kaiserlichen Akademie der Wissenschaften, 60: 351-404.

48. Waltzing J.-P. 1895. Etude historique sur les corporations professionnelles chez les romains depuis les origines jusqu'd la chute de l'empire d'occident. Louvain, C. Peeters, 741.

49. Weiss J. 1917. Das Urchristentum. Gottingen, Vandenhoeck \& Ruprecht, 681.

Westberg D. 2010. Celebrating with Words: Studies in the Rhetorical Works of the Gaza School. Diss. Uppsala Universiteit, 225. 
Via in tempore. История. Политология. 2021. Том 48, № 1 (36-47)

Via in tempore. History and political science. 2021. Volume 48, № 1 (36-47)

\section{ИНФОРМАЦИЯ ОБ АВТОРЕ}

Лопатина Марина Юрьевна, аспирант кафедры всеобщей истории Белгородского государственного национального

исследовательского университета, г. Белгород, Россия

\section{INFORMATION ABOUT THE AUTHOR}

Marina Yu. Lopatina, postgraduate of the Department of general history, Belgorod National Research University, Belgorod, Russia 